\title{
Implementasi Web Media Sosial Di Program Studi Informatika Universitas Sam Ratulangi
}

\author{
Kristopper M Rompis, Steven R. Sentinuwo, Xaverius B.N. Najoan \\ Teknik Informatika Universitas Sam Ratulangi Manado \\ Jl. Kampus UNSRAT Bahu, 95115 \\ kakbassistcakep@gmail.com, steven@unsrat.ac.id, xnajoan@unsrat.ac.id
}

\begin{abstract}
Abstrak - Perkembangan teknologi internet saat ini berkembang pesat, hal ini juga berpengaruh pada perkembangan website misalnya dalam hal ini website media sosial. Untuk itu peneliti akan mengimplementasikan web media sosial di prodi informatika UNSRAT. Dalam pembuatan media sosial ini, akan menggunakan Bahasa pemgrograman PHP (Hypertext Preprocessor) dalam penanganan dan pembuatan web dan untuk databasenya masih menggunakan MySQL serta peneliti juga menggunakan framework yang bernama CI (Codeigniter) yang menggunakan konsep MVC ( Model, View, Controller). Hasil dari penelitian ini ada pembuatan database dan tampilan website serta fungsi-fungsi yang ada dalam web media sosia.
\end{abstract}

Kata kunci : Media Sosial, Informatika Unsrat, Php, Codeigniter

\section{PENDAHULUAN}

Pada awalnya, teknologi informasi dibuat untuk mempermudah aktivitas manusia. Dan kini kecanggihan teknologi informasi komunikasi itu semakin maju sehingga terjadi penambahan fungsi dalam bidang teknologi informasi komunikasi yang semakin mempermudah dan memanjakan manusia dan contoh salah satu kecanggihan teknologi yaitu media sosial. Media sosial saat ini sedang diminati oleh semua orang dimuka bumi ini. Orang kaya, orang miskin, pelajar, mahasiswa, orang tua, anak muda, orang kota, orang desa berlomba- lomba mengakses jejaring sosial dimanapun dan kapanpun selama jaringan internet ada. Ini berarti orang-orang sekarang ingin lebih banyak berbagi dengan orang-orang yang jauh yang dikenal maupun tak dikenal serta dapat mendapatkan berbagai informasi yang dibutuhkan.

Pada tahun 2014 Tim Pusat Humas Kementerian Perdagangan RI menjelaskan bahwa media sosial bisa dikatakan sebagai media online, di mana para penggunanya (user) melalui aplikasi berbasis internet dapat berbagi, berpartisipasi, dan menciptakan konten berupa blog, wiki, forum, jejaring sosial dan ruang dunia virtual yang disokong oleh teknologi multimedia yang kian canggih. Merebaknya situs medsos yang muncul menguntungkan banyak orang dari berbagai belahan dunia untuk berinteraksi dengan mudah dan dengan ongkos yang murah ketimbang memakai telepon.
Dampak positif yang lain dari adanya situs jejaring sosial adalah percepatan penyebaran informasi. Media sosial juga sangat dibutuhkan dalam dunia kampus, dimana kampus itu tempatnya mahasiswa-mahasiswa berkumpul dan memerlukan media sosial untuk membagikannya kepada teman-teman kuliahnya. Mungkin dalam media sosial seperti facebook atau twitter yang popular saat ini dimana lebih ditekankan dalam hubungan interaksi kesemua orang tanpa harus membatasi, artinya bisa berbagi kepada siapa saja.

Program Studi (Prodi) Informatika Universitas Sam Ratulangi (UNSRAT) telah mempunyai media komunikasi seperti Portal Akademik dan E-Learning. Salah satu permasalahan yang sering terjadi di kalangan mahasiswa khususnya dalam Prodi Informatika UNSRAT adalah kurang efektifnya pemberian informasi yang diberikan oleh dosen kepada mahasiswa, hal tersebut dikarenakan informasi hanya diberikan oleh dosen kepada salah satu mahasiswa untuk disebarkan kepada mahasiswa lainnya sehingga informasi yang didapat sering simpang siur. Media sosial yang digunakan oleh hampir semua kalangan saat ini dapat dimanfaatkan untuk mengatasi permasalahan tidak efektifnya pemberian informasi tersebut, sehingga pemberian tugas, perubahan jadwal kuliah, pengumuman kegiatan dan lain sebagainya dapat langsung diumumkan melalui media sosial. Akan tetapi dibutuhkan aplikasi website media sosial yang khusus untuk kegiatan perkuliahan sekaligus interaksi yang melibatkan dosen dan mahasiswa yang ada di Prodi Informatika UNSRAT.

Jadi berdasarkan uraian yang ada diatas, maka penulis akan membuat penelitian tentang penggunaan website media sosial pada Prodi Informatika UNSRAT dengan judul "Implementasi Website Media Sosial pada Program Studi Informatika Universitas Sam Ratulangi”.

Jejaring sosial merupakan situs dimana setiap orang bisa membuat web page pribadi, kemudian terhubung dengan teman-teman untuk berbagi informasi dan berkomunikasi. Jejaring sosial terbesar antara lain Facebook dan Twitter. Jika media tradisional menggunakan media cetak dan media broadcast, maka media sosial menggunakan internet. Media sosial mengajak siapa saja yang tertarik untuk berpartisipasi dengan memberi kontribusi dan feedback secara terbuka, memberi komentar, serta membagi informasi dalam 
waktu yang cepat dan tak terbatas. Media sosial mempunyai ciri-ciri, yaitu sebagai berikut :

- Pesan yang di sampaikan tidak hanya untuk satu orang saja namun bisa ke berbagai banyak orang contohnya pesan melalui SMS ataupun internet.

- Pesan yang di sampaikan bebas, tanpa harus melalui suatu Gatekeeper.

- Pesan yang di sampaikan cenderung lebih cepat di banding media lainnya.

- Penerima pesan yang menentukan waktu interaksi.

Adapun Fitur-fitur yang harus terdapat pada sebuah aplikasi media sosial adalah sebagai berikut.

- Sociality

Media sosial dapat disebut sebuah komunitas dan media ini fokus pada adanya pertukaran informasi. Jadi, sebuah aplikasi media sosial harus mempunyai fitur untuk para penggunanya agar dapat saling bertukar informasi.

- Openness

Media sosial biasanya tidak mempunyai jumlah pengguna yang ditentukan sebelumnya. Media sosial mempunyai jumlah yang besar dan tidak dapat didefinisikan secara pasti jumlahnya. Semua orang dapat berpatisipasi dan berkontribusi secara bebas sesuai keinginan mereka tidak ada tuntutan atau perintah pihak lain.

\section{- Contributors}

Kontributor di media sosial adalah seorang individu yang bebas dan tidak terikat dengan salah satu pihak atau lebih. Jadi, berpartisipasinya seorang individu untuk menjadi kotributor media sosial tergantung dari individu itu sendiri.

\section{- Contents}

Isi dari informasi yang dihasilkan dari sebuah media sosial adalah user-generated. Jadi, informasi pada sebuah aplikasi media sosial berasal dari pengguna dan informasi tersebut digunakan untuk pengguna pula.

\section{- Technology}

Sebuah aplikasi media sosial biasanya mudah digunakan dan merupakan open source software.

- Location

Sistem aplikasi media sosial adalah online. Jadi, pengguna aplikasi media sosial dapat berasal dari banyak lokasi asalkan terdapat koneksi internet.

\section{METODOLOGI PENELITIAN}

Menurut Hamzah, H dkk (2016) metodologi penelitian berisi langkah-langkah yang digunakan dalam penelitian ini agar terstruktur dengan baik. Dengan sistematika ini proses penelitian dapat dipahami dan diikuti oleh pihak lain. Penelitian yang dilakukan untuk merancang sistem diperoleh dari pengamatan data-data yang ada. Adapun langkah-langkah yang dilakukan untuk mencapai tujuan dari penelitian ini adalah seperti Gambar 1.

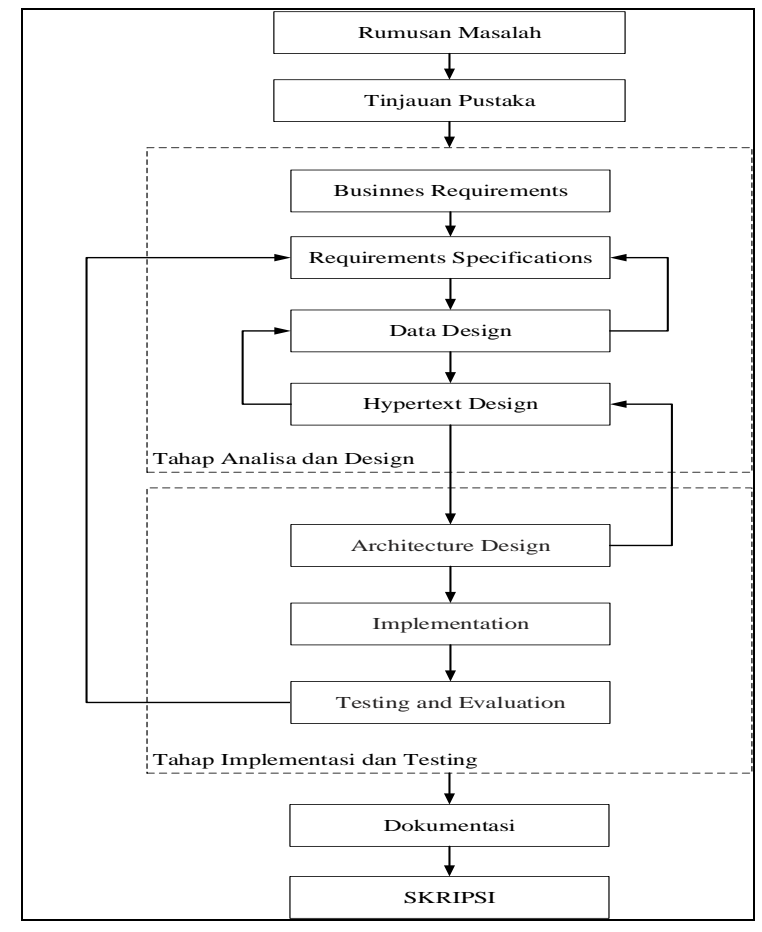

Gambar 1. Kerangka Pikir

\section{Tahap Analisa Dan Design}

a. Web Modeling Languange (WebML)

Menurut Janner Simarmata (2010:224), WebML merupakan bahasa spesifikasi tingkat tinggi untuk aplikasi hypermedia. WebML mengijinkan style keduanya, yaitu Entity-Relationship dan UML, untuk menawarkan notasi yang tepat dan representasi grafik menggunakan sintaks UML. Menurut Adam Bosword (2003:193) dalam bukunya yang berjudul "Designing Data-Intensive Web Application" WebML memungkinkan desainer untuk mengekspresikan fitur inti dari sebuah situs pada tingkat tinggi, tanpa melakukan rincian detail untuk arsitekturnya. Konsep WebML berhubungan dengan representasi grafis yang dapat dengan mudah didukung oleh C.A.S.E. (Computer Aided Software Engineering) tools dan efektif dikomunikasikan kepada anggota non-teknis dari tim pengembangan situs (misalnya, dengan desainer grafis dan produsen).

\section{b. Requirements Specification}

Merupakan kegiatan di mana analis aplikasi mengumpulkan dan meresmikan informasi penting tentang domain aplikasi dan fungsi yang diharapkan. Input requirements specification terdiri dari kumpulan business requirements yang memotivasi dalam pengembangan aplikasi dan semua informasi yang tersedia pada konteks teknis, organisasi dan pengolahan di mana aplikasi harus beroperasi. Output requirements specification terdiri dari kebutuhan pengguna, mudah dipahami, harus teliti, spesifikasi, yang ditujukan baik untuk para perancang, agar yang menggunakannya dapat memahami apa yang harus dilakukan dengan aplikasi 
tersebut, dan kepada Stakeholder, yang menggunakan untuk memvalidasi kebutuhan untuk website media sosial dari spesifikasi business requirements, sebelum dilanjutkan oleh development.

\section{c. Data Design}

Data design merupakan fase di mana ahli data mengatur objek informasi utama yang diidentifikasi selama persyaratan spesifikasi menjadi model data konseptual yang comprehensive dan coherent. Pemodelan data yang paling popular adalah konseptual model data, model entity relationship, pemodelan data untuk aplikasi Web memiliki aroma khusus, karena peran yang objek informasi bermain dalam konteks seperti itu. Dengan demikian, metode desain data dibahas dalam Bab 4 disesuaikan dengan aplikasi Web. Ini berfokus pada desain khas sub-skema yang menggambarkan objek aplikasi inti, data kategorisasi diperlukan untuk mengaksesnya, interkoneksi antara inti objek yang diperlukan untuk navigasi, dan data personalisasi.

\section{Hypertext Design}

Hypertext design merupakan aktivitas yang mengubah persyaratan fungsional yang diidentifikasi dari requirements specification menjadi satu atau lebih tampilan situs. Hypertext design beroperasi pada tingkat konseptual, mengeksploitasi model WebML, yang memungkinkan hypertext menentukan bagaimana unit didefinisikan dalam objek data, terdiri dalam halaman dan bagaimana unit dan halaman yang terhubung dengan link untuk membentuk hypertext. Tidak seperti data design, pemodelan hypertext konseptual merupakan disiplin baru dengan dukungan metodologi.

\section{HASIL DAN PEMBAHASAN}

\section{Arsitektur Desain}

\section{a. Database}

Perancangan struktur database ini untuk membuat struktur tabel yang digunakan dalam penyimpanan data pada aplikasi system informasi yang dibuat. Struktur data yang digunakan pada aplikasi ini menggunakan MySQL dan berikut adalah rancangan tabel yang digunakan.

Tabel 1. Database

\begin{tabular}{|l|l|l|l|l|}
\hline No & $\begin{array}{l}\text { Nama } \\
\text { Tabel }\end{array}$ & $\begin{array}{l}\text { Nama } \\
\text { Datab } \\
\text { ase } \\
\text { Tabel }\end{array}$ & $\begin{array}{l}\text { Primary } \\
\text { Key }\end{array}$ & Deskripsi \\
\hline 1. & User & db_ta & $\begin{array}{c}\text { Userna } \\
\text { me }\end{array}$ & $\begin{array}{l}\text { Untuk } \\
\text { menyimpan } \\
\text { data data user }\end{array}$ \\
\hline 2. & Dosen & db_ta & - & $\begin{array}{l}\text { Untuk } \\
\text { menyimpan } \\
\text { data-data user }\end{array}$ \\
\hline
\end{tabular}

\begin{tabular}{|c|c|c|c|c|}
\hline & & & & $\begin{array}{l}\text { yang ada } \\
\text { pada dosen }\end{array}$ \\
\hline 3. & $\begin{array}{c}\text { Mahasis } \\
\text { wa }\end{array}$ & db_ta & - & $\begin{array}{l}\text { Untuk } \\
\text { menyimpan } \\
\text { data-data } \\
\text { yang ada } \\
\text { pada } \\
\text { mahasiswa }\end{array}$ \\
\hline 4. & $\begin{array}{c}\text { Pertanya } \\
\text { an }\end{array}$ & db_ta & - & $\begin{array}{l}\text { Untuk } \\
\text { menyimpan } \\
\text { semua data- } \\
\text { data } \\
\text { pertanyaan } \\
\text { yang diajukan } \\
\text { oleh user }\end{array}$ \\
\hline 5. & Jawaban & db_ta & - & $\begin{array}{l}\text { Untuk } \\
\text { menyimpan } \\
\text { semua data- } \\
\text { data jawaban } \\
\text { yang } \\
\text { diberikan } \\
\text { oleh user } \\
\text { untuk } \\
\text { menjawab } \\
\text { pertanyaan }\end{array}$ \\
\hline 6. & Ikuti & db_ta & id_ikuti & $\begin{array}{l}\text { Untuk } \\
\text { menyimpan } \\
\text { data user } \\
\text { yang } \\
\text { mengikuti } \\
\text { atau } \\
\text { mempunyai } \\
\text { pertanyaan } \\
\text { yang sama }\end{array}$ \\
\hline 7. & $\begin{array}{l}\text { Pengumu } \\
\text { man }\end{array}$ & db_ta & $\begin{array}{l}\text { id_peng } \\
\text { umuma } \\
n\end{array}$ & $\begin{array}{l}\text { Untuk } \\
\text { menyimpan } \\
\text { semua data- } \\
\text { data } \\
\text { mengenai } \\
\text { pengumuman } \\
\text { yang } \\
\text { diberikan } \\
\text { user }\end{array}$ \\
\hline 8 & Grup & db_ta & $\begin{array}{c}\text { nama_g } \\
\text { rup }\end{array}$ & $\begin{array}{l}\text { Untuk } \\
\text { menyimpan } \\
\text { data-data } \\
\text { yang ada } \\
\text { pada database } \\
\text { grup }\end{array}$ \\
\hline 9. & $\begin{array}{l}\text { Komenta } \\
\text { rgrup }\end{array}$ & db_ta & $\begin{array}{c}\text { Komen } \\
\text { grup }\end{array}$ & $\begin{array}{l}\text { Untuk } \\
\text { menyimpan } \\
\text { data-data } \\
\text { yang ada } \\
\text { pada database }\end{array}$ \\
\hline
\end{tabular}




\begin{tabular}{|l|l|l|l|l|}
\hline & & & $\begin{array}{l}\text { komentar } \\
\text { grup }\end{array}$ \\
\hline 10. & Pesan & db_ta & $\begin{array}{r}\text { id_pesa } \\
\text { n }\end{array}$ & $\begin{array}{l}\text { Untuk } \\
\text { menyimpan } \\
\text { data-data } \\
\text { yang ada } \\
\text { pada database } \\
\text { pesan }\end{array}$ \\
\hline
\end{tabular}

b. Relasi Database

Relasi database pada aplikasi web media sosial ini dengan pemrogram PHP dan MySQL sebagai berikut :

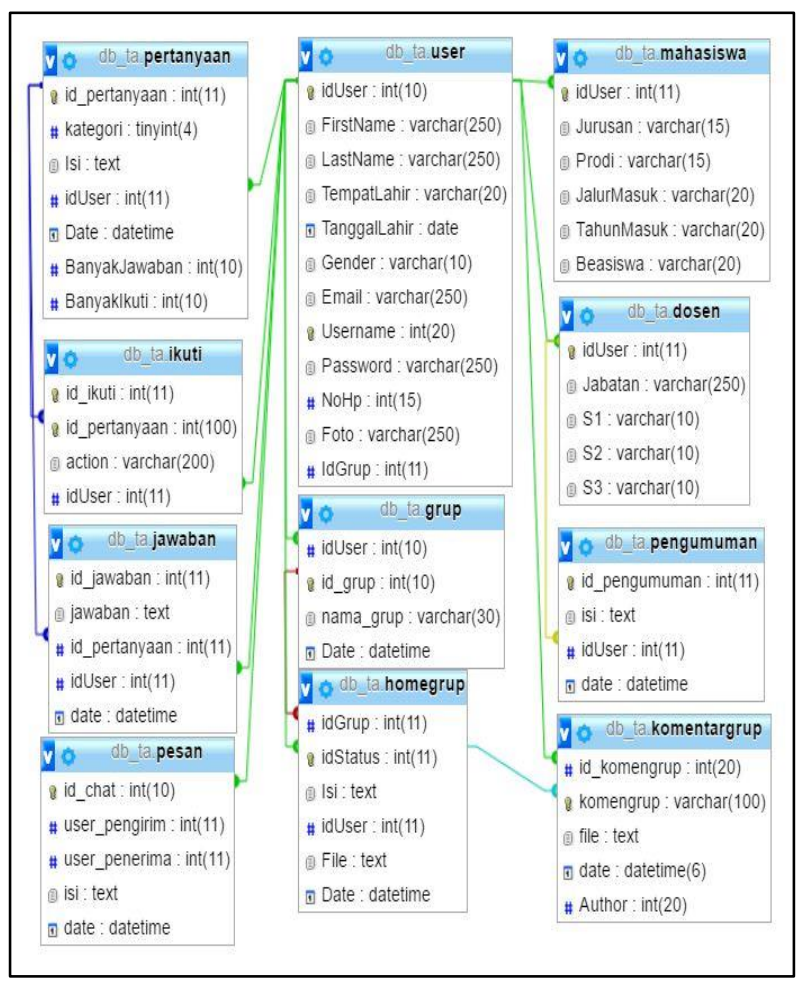

Gambar 2. Relasi Antar Tabel

\section{c. Model View Controller Aplikasi}

Pada aplikasi pembuatan web media sosial ini meggunakn framework php yaitu Codeigniter yang menggunakan konsep MVC atau Model View Controller. Berikut adalah Model View Controller dari aplikasi ini.
Tabel 3. List Model

\begin{tabular}{|l|l|l|}
\hline No & Nama Model & \multicolumn{1}{|c|}{ Deskripsi } \\
\hline 1. & Detail & $\begin{array}{l}\text { Model data yang memuat } \\
\text { tentang data-data profil } \\
\text { user yang disimpan } \\
\text { didatabase }\end{array}$ \\
\hline 2 & Ikuti_mod & $\begin{array}{l}\text { Model data yang memuat } \\
\text { tentang data-data yang } \\
\text { mempunyai jika ada } \\
\text { pertanyaan yang sama }\end{array}$ \\
\hline 3. & Pertanyaan & $\begin{array}{l}\text { Model data yang memuat } \\
\text { tentang data-data mengenai } \\
\text { isi pertanyaan }\end{array}$ \\
\hline 4. & Jawaban & $\begin{array}{l}\text { Model data yang memuat } \\
\text { tentang data-data mengenai } \\
\text { isi jawaban }\end{array}$ \\
\hline 5 & Log_mod & $\begin{array}{l}\text { Model data yang memuat } \\
\text { data-data user }\end{array}$ \\
\hline 6. & $\begin{array}{l}\text { Pengumuman } \\
\text { mod }\end{array}$ & $\begin{array}{l}\text { Model data yang memuat } \\
\text { data-data pengumuman }\end{array}$ \\
\hline
\end{tabular}

Tabel 2. List View

\begin{tabular}{|c|c|l|l|}
\hline No & $\begin{array}{c}\text { Nama } \\
\text { View }\end{array}$ & Data Dari Controller & Deskripsi \\
\hline 1. & Login & & $\begin{array}{l}\text { Untuk } \\
\text { menampilka } \\
\text { interface } \\
\text { tampilan } \\
\text { login }\end{array}$ \\
\hline 2. & Home & $\begin{array}{l}\text { \$profilepic, \$Nama, } \\
\text { \$Username }\end{array}$ & $\begin{array}{l}\text { Untuk } \\
\text { menampilka } \\
\text { n interface } \\
\text { tampilan } \\
\text { home }\end{array}$ \\
\hline 3. & $\begin{array}{l}\text { Berita } \\
\text { Timel } \\
\text { ine }\end{array}$ & $\begin{array}{l}\text { \$list['Date], } \\
\text { \$list['Isi'], } \\
\text { \$list['BanyakIkuti'], } \\
\text { \$coment['Foto'], } \\
\text { \$coment['FirstName' } \\
\text { ], } \\
\text { \$coment['LastName'] } \\
\text { \$coment['Date'], } \\
\text { \$coment['Jawaban'], } \\
\text { \$list['id_pertanyaan'], } \\
\text { \$list['Foto'], } \\
\text { \$list['FirstName'], } \\
\text { \$list['LastName'], } \\
\text { \$list['Date'], } \\
\text { \$list['Isi'] }\end{array}$ & $\begin{array}{l}\text { Untuk } \\
\text { menampilka } \\
\text { tampilan } \\
\text { informasi }\end{array}$ \\
\hline
\end{tabular}




\begin{tabular}{|c|c|c|c|}
\hline 4 & $\begin{array}{l}\text { Pengu } \\
\text { muma } \\
n\end{array}$ & $\begin{array}{l}\text { \$list['Foto'], } \\
\text { \$list['FirstName'], } \\
\text { \$list['LastName'], } \\
\text { \$list['Date'], } \\
\text { \$list['isi'] }\end{array}$ & $\begin{array}{l}\text { Untuk } \\
\text { menampilka } \\
\mathrm{n} \text { interface } \\
\text { pada } \\
\text { tampilan } \\
\text { pengumuma } \\
\text { n. }\end{array}$ \\
\hline 5 & Profil & $\begin{array}{l}\text { \$detail['Foto'], } \\
\text { \$detail['FirstName'], } \\
\text { \$detail['LastName'], } \\
\text { \$detail['FirstName'], } \\
\text { \$detail['Username'], } \\
\text { \$detail['TempatLahir] } \\
\text {, } \\
\text { \$detail['TanggalLahir } \\
\text { '], } \\
\text { \$detail['Gender'], } \\
\text { \$detail['Email'], } \\
\text { \$detail['NoHp'], } \\
\text { \$detail['Jurusan'], } \\
\text { \$detail['Prodi'], } \\
\text { \$detail['TahunMasuk } \\
\text { '], } \\
\text { \$detail['JalurMasuk'], } \\
\text { \$detail['Beasiswa'] }\end{array}$ & $\begin{array}{l}\text { Untuk } \\
\text { menampilka } \\
\mathrm{n} \text { interface } \\
\text { tampilan } \\
\text { profil }\end{array}$ \\
\hline 6. & $\begin{array}{l}\text { Penga } \\
\text { turan }\end{array}$ & - & $\begin{array}{l}\text { Untuk } \\
\text { menampilka } \\
\mathrm{n} \\
\text { pengaturan } \\
\text { profil }\end{array}$ \\
\hline 7. & $\begin{array}{c}\text { Pemb } \\
\text { eritah } \\
\text { uan }\end{array}$ & & $\begin{array}{l}\text { Untuk } \\
\text { menampilka } \\
\mathrm{n} \text { interface } \\
\text { tampilan } \\
\text { pemberitahu } \\
\text { an }\end{array}$ \\
\hline 8 & $\begin{array}{l}\text { Maca } \\
\text { m } \\
\text { Grup }\end{array}$ & - & $\begin{array}{l}\text { Untuk } \\
\text { menampilka } \\
\mathrm{n} \text { interface } \\
\text { tampilan } \\
\text { grup }\end{array}$ \\
\hline 9 & Grup & - & $\begin{array}{l}\text { Untuk } \\
\text { menampilka } \\
\mathrm{n} \text { interface } \\
\text { tampilan } \\
\text { grup }\end{array}$ \\
\hline 10. & Pesan & - & $\begin{array}{l}\text { Untuk } \\
\text { menampilka } \\
\mathrm{n} \text { interface } \\
\text { tampilan } \\
\text { pesan }\end{array}$ \\
\hline
\end{tabular}

\begin{tabular}{|c|c|c|c|}
\hline 11. & Detail & - & $\begin{array}{l}\text { Untuk } \\
\text { menampilka } \\
\mathrm{n} \text { interface } \\
\text { tampilan } \\
\text { detail pesan }\end{array}$ \\
\hline 12. & $\begin{array}{c}\text { Layo } \\
\text { ut }\end{array}$ & $\begin{array}{c}\text { Layout login, layout } \\
\text { login2, Layout } \\
\text { frontpage, Layout } \\
\text { sites_default, Layout } \\
\text { sites_default1, Layout } \\
\text { sites_default2, Layout } \\
\text { sites_macamgrup, } \\
\text { Layout sites_grup, } \\
\text { Layout sites_anggota, } \\
\text { Layout } \\
\text { sites_pemberitahuan, } \\
\text { Layout } \\
\text { sites_komentar, } \\
\text { Layout sites_pesan, } \\
\text { Layout detail, Layout } \\
\text { sites_pengaturan, } \\
\text { Layout pengumuman }\end{array}$ & $\begin{array}{l}\text { Untuk } \\
\text { memanggil } \\
\text { interface } \\
\text { tampilan } \\
\text { yang telah } \\
\text { diinialisasi } \\
\text { agar } \\
\text { mengurangi } \\
\text { coding } \\
\text { tampilan } \\
\text { yang terlalu } \\
\text { banyak. }\end{array}$ \\
\hline 13. & Blank & - & $\begin{array}{l}\text { Untuk } \\
\text { menampilka } \\
\mathrm{n} \text { interface } \\
\text { tampilan } \\
\text { dari error } \\
\text { aplikasi }\end{array}$ \\
\hline 14 & Body & - & $\begin{array}{l}\text { Untuk } \\
\text { menampilka } \\
\mathrm{n} \text { interface } \\
\text { tampilan } \\
\text { dari body } \\
\text { pengisian } \\
\text { status } \\
\text { pertanyaan }\end{array}$ \\
\hline 15 & $\begin{array}{l}\text { Head } \\
\text { er }\end{array}$ & - & $\begin{array}{l}\text { Untuk } \\
\text { menampilka } \\
\mathrm{n} \text { interface } \\
\text { tampilan } \\
\text { header }\end{array}$ \\
\hline 16 & $\mathrm{Nav}$ & - & $\begin{array}{l}\text { Untuk } \\
\text { menampilka } \\
\mathrm{n} \text { interface } \\
\text { tampilan } \\
\text { navigasi }\end{array}$ \\
\hline
\end{tabular}

Tabel 2. List Controller

\begin{tabular}{|l|l|c|}
\hline No & Nama Controller & Deskripsi \\
\hline 1. & Login & $\begin{array}{c}\text { Controller yang } \\
\text { memproses } \\
\text { permintaan user }\end{array}$ \\
\hline
\end{tabular}




\begin{tabular}{|c|c|c|}
\hline & & $\begin{array}{c}\text { ketika akan } \\
\text { melakukan proses } \\
\text { login }\end{array}$ \\
\hline 2. & Home & $\begin{array}{c}\text { Controller yang } \\
\text { memproses seluruh } \\
\text { permintaan user di } \\
\text { home }\end{array}$ \\
\hline 3. & Informasi & $\begin{array}{l}\text { Controller yang } \\
\text { memproses seluruh } \\
\text { permintaan user } \\
\text { mengenai data } \\
\text { informasi }\end{array}$ \\
\hline 4. & Profil & $\begin{array}{l}\text { Controller yang } \\
\text { memproses seluruh } \\
\text { permintaan user } \\
\text { mengenai data profil }\end{array}$ \\
\hline 5. & Macam Grup & $\begin{array}{l}\text { Controller yang } \\
\text { memproses seluruh } \\
\text { permintaan user } \\
\text { mengenai data } \\
\text { macam grup }\end{array}$ \\
\hline 6. & Pemberitahuan & $\begin{array}{l}\text { Controller yang } \\
\text { memproses seluruh } \\
\text { permintaan user } \\
\text { mengenai data } \\
\text { pemberitahuan }\end{array}$ \\
\hline 7. & Pesan & $\begin{array}{l}\text { Controller yang } \\
\text { memproses seluruh } \\
\text { permintaan user } \\
\text { mengenai data pesan }\end{array}$ \\
\hline
\end{tabular}

\section{d. View Aplikasi}

Dalam tampilan user yang telah dibahas oleh Hamzah, H dkk (2016) terdapat isi berupa status yang bisa dikomentar atau disukai. Ada tujuh area dalam tampilan ini yaitu Login, Beranda, Grup, Profil, Pencarian, Pesan dan Pemberitahuan.

\section{Implementation}

Tahap implementasi system merupakan proses yang dilakukan setelah tahap perancangan selesai dilaksanakan. Tujuan yang dicapai pada tahap ini adalah dapat dioperasikannya hasil perancangan system yang telah dibuat. Pada tahap ini akan dijelaskan mengenai Sistem yang dirancang dan bagaimana cara penggunaannya.

\section{a. Implementasi Perangkat Lunak}

Adapun perangkat lunak yang harus disiapkan dalam pembuatan aplikasi web media sosial diprodi informatika unsrat ini yaitu melakukan beberapa development tools yang dilakukan, antara lain :

- Database Server

Database server yang digunakan adalah server database MySql untuk menyimpan sumber data aplikasi.

- Codeigniter

Sebagai media untuk penulisan script php yang menggunakan Model, View, Controller

- PHP

Digunakan sebagai script atau Bahasa pemrograman yang digunakan.

- Google Crome

Sebagai media untuk menampilkan aplikasi web media sosial Prodi Informatika UNSRAT.

a. Implementasi Perangkat keras

Perangkat keras yang digunakan dalam pembuatan aplikasi web ini antara lain:

- $\quad$ Processor core i3

- $\quad$ Ram $4 \mathrm{~Gb}$

- VGA $1 \mathrm{~Gb}$

- DVD Rw

- Laptop atau Personal Computer

b. Implementasi Interface Aplikasi

Halaman ini berisi mengenai fitur-fitur yang dapat diakses oleh user mengenai cara-cara penggunaan aplikasi web media sosial di prodi informatika. Untuk lebih detailnya akan dijelaskan secara berikut:

\section{- Halaman Login}

User hanya perlu menginputkan username dan password yang telah tersimpan dalam database dengan benar dapat dilihat pada gambar 3 .

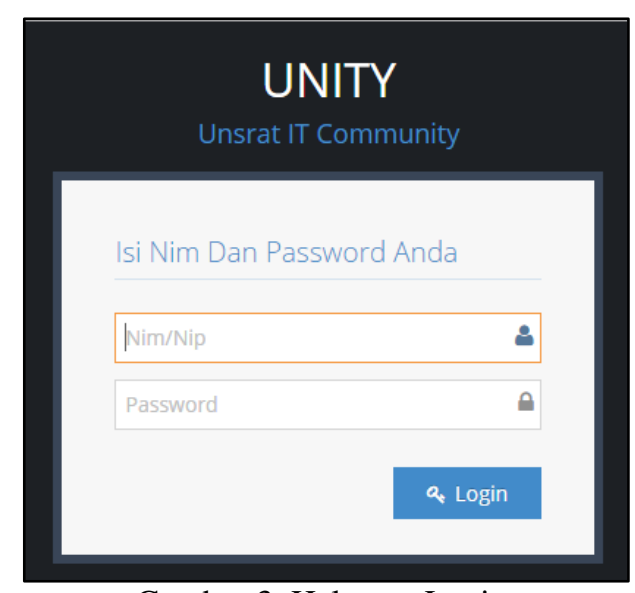

Gambar 3. Halaman Login 


\section{- Halaman Home}

Pada gambar 4 menjelaskan bahwa user berhasil login maka user akan masuk ke halaman home dimana user akan masuk pada menu-menu yang telah di sediakan.

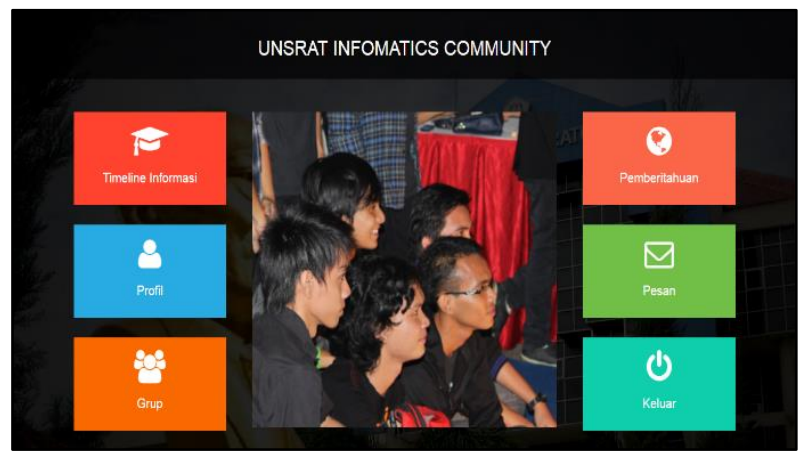

Gambar 4. Halaman Home

\section{- Halaman Timeline Informasi}

Pada gambar 5 dimana user masuk pada menu timeline informasi, maka disitu akan ditampilkan seluruh informasi tentang pertanyaan-pertanyaan serta pengumuman yang disimpan didatabase.

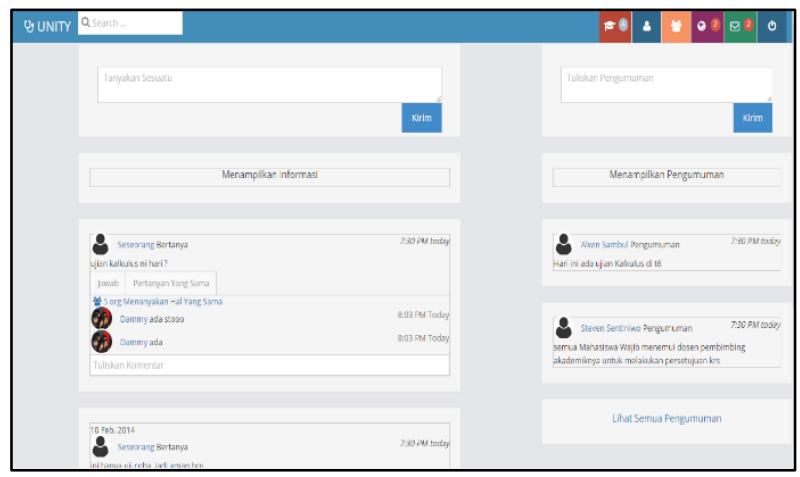

Gambar 5. Halaman Timeline Informasi

\section{- Halaman Pengumuman}

Didalam timeline informasi terdapat link untuk melihat semua pengumuman. Dan ketika user mengklik lihat semua pengumuman maka user akan pergi ke halaman pengumuman dilihat pada gambar 6 .

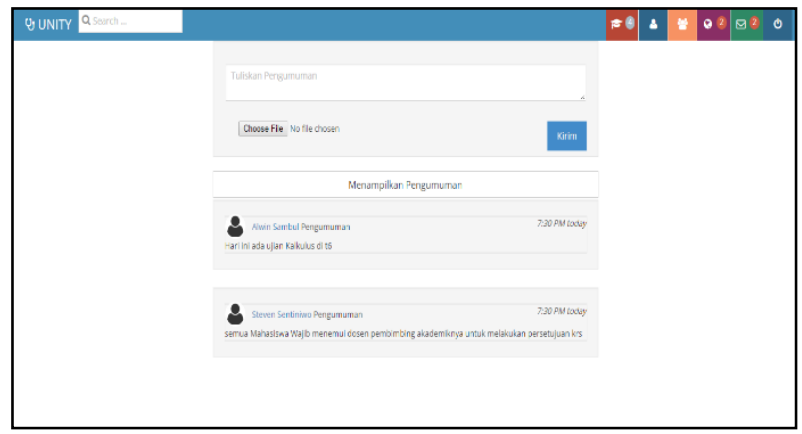

Gambar 6. Halaman Pengumuman
- Halaman Profil

Didalam halaman profil ini menunjukan identitas si user dilihat pada gambar 7 .

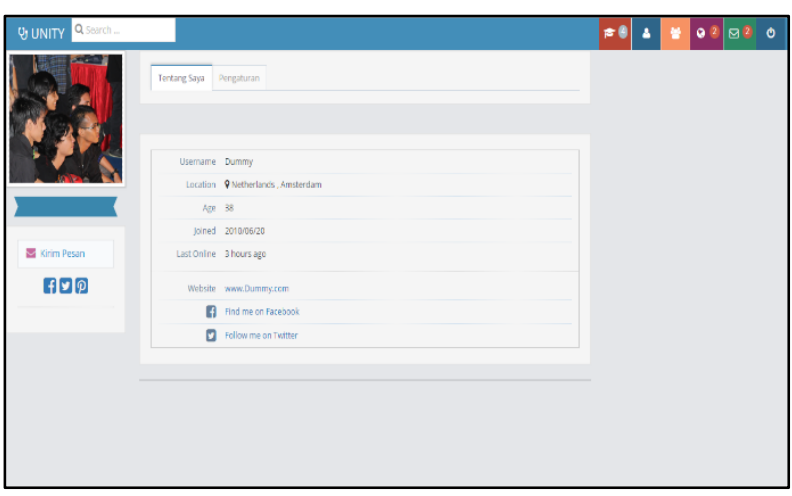

Gambar 7. Halaman Profil

\section{- Halaman Pengaturan}

Pada gambar 8 menjelaskan halaman profil terdapat link kepengaturan yang berfungsi untuk mengubah kembali data-data si user.

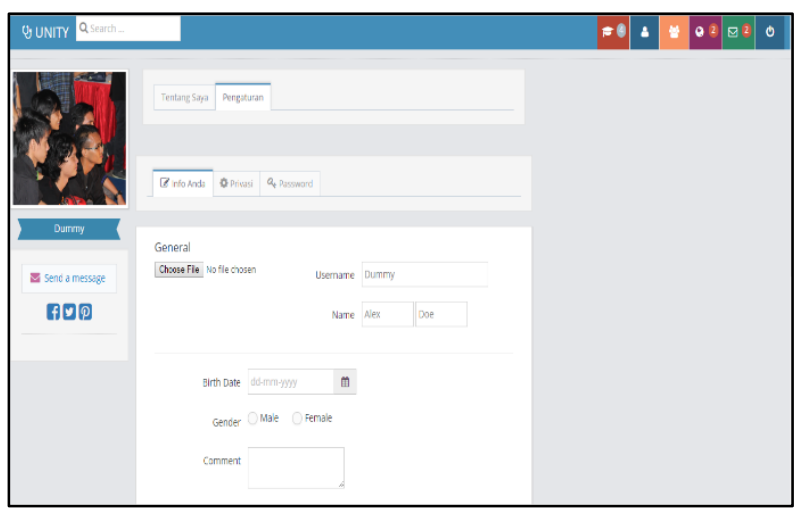

Gambar 8. Halaman Pengaturan

\section{- Halaman Daftar Grup}

Halaman ini menunjukan si user bergabung dengan grup mana, serta ada link membuat grup baru dilihat pada gambar 9 .

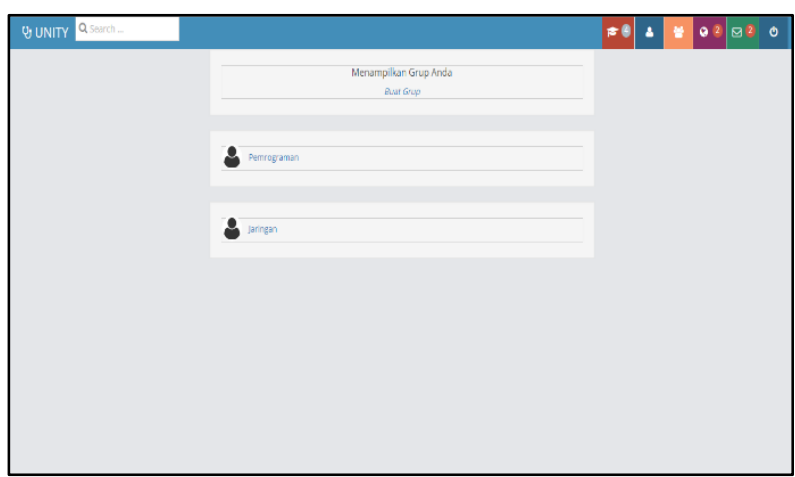

Gambar 9. Halaman Daftar Grup 


\section{- Halaman Grup}

Pada gambar 10 menjelaskan halaman ini terdapat informasi yang dibagikan dan hanya bisa dilihat oleh user yang mengikutinya.

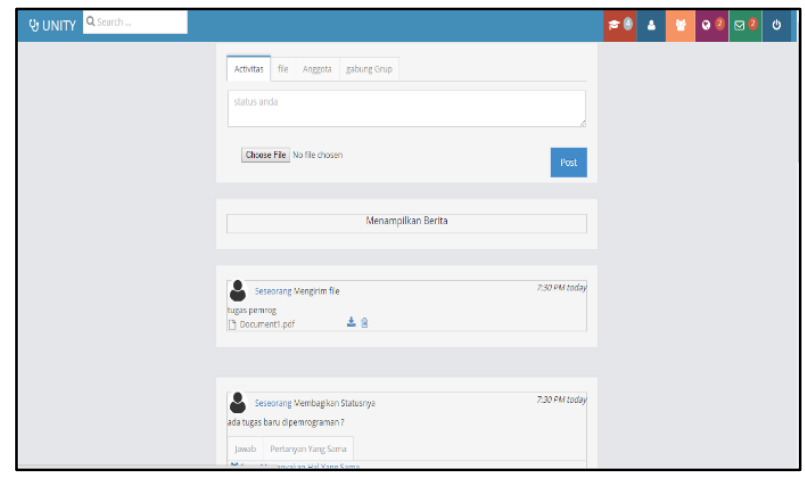

Gambar 10. Halaman Grup

- Halaman File

Didalam halaman grup terdapat link ke menu file. Jika user masuk kemenu file maka dia akan pergi kehalaman file dimana terdapat file-file yang pernah dibagikan bisa dilihat pada gambar 11.

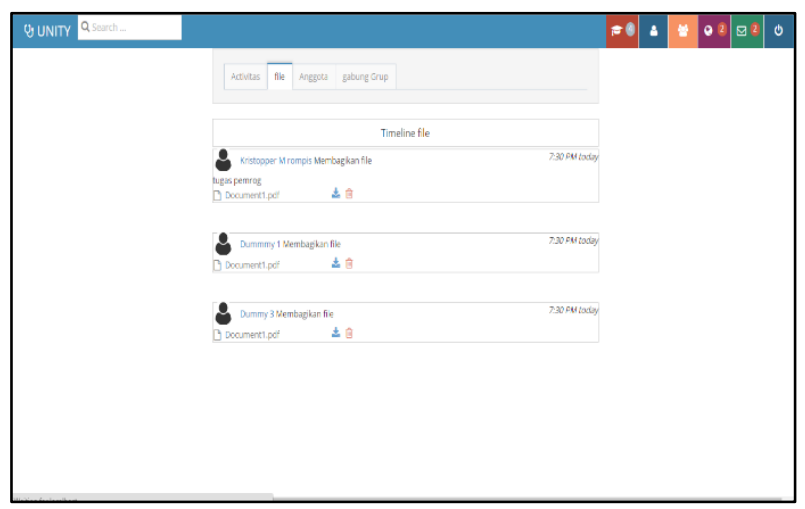

Gambar 11. Halaman File

\section{- Halaman Anggota}

Didalam halaman grup juga terdapat link ke menu anggota. Jika user masuk kemenu angggota maka dia akan pergi kehalaman anggota dimana terdapat anggota yang pernah bergabung dilihat pada gambar 12 .

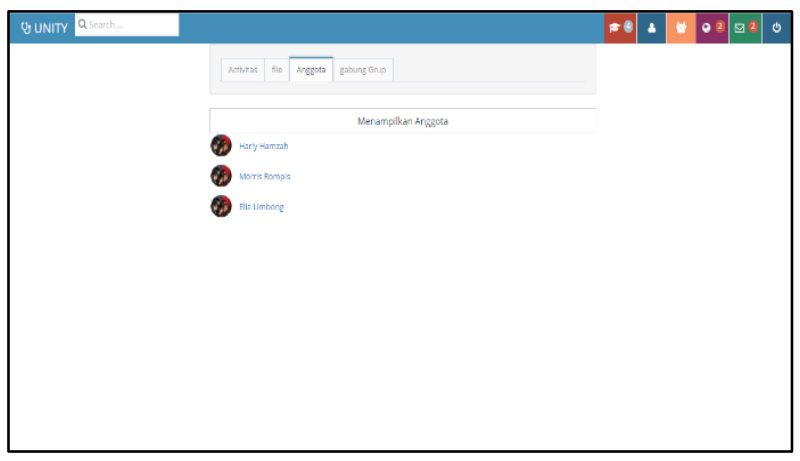

Gambar 12. Halaman Anggota

\section{- Halaman Pemberitahuan}

Pada gambar 13 menjelaskan dalam halaman ini user diberitahukan jika adanya sesuatu hal yang berhubungan dengan si user.

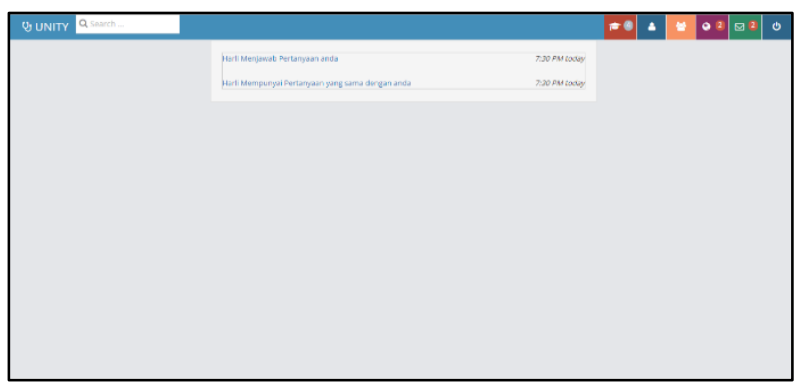

Gambar 13. Halaman Pembertitahuan

\section{- Halaman Pesan}

Halaman PemberitahuanHalaman ini menunjukan semua pesan yang dikirim atau terkirim dilihat pada gambar 14.

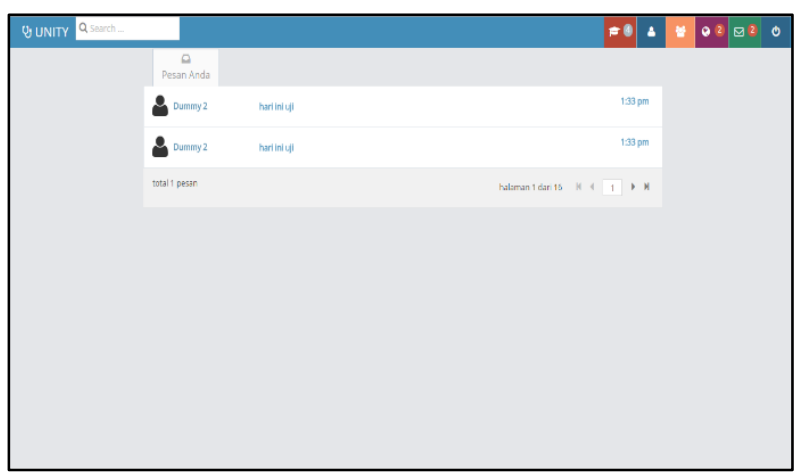

\section{Gambar 14. Halaman Pesan}

\section{- Halaman Baca Pesan}

Pada gambar 15 menjelaskan halaman ini adalah halaman untuk membaca pesan serta membalas pesan yang masuk.

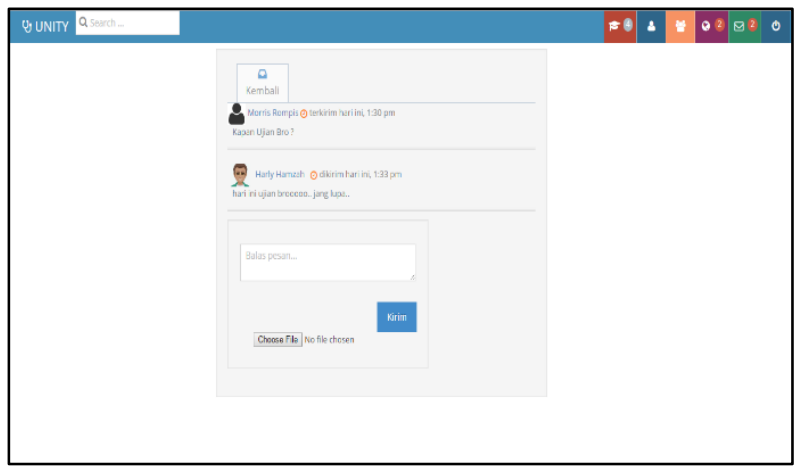

Gambar 15. Halaman Baca Pesan

\section{Testing Dan Evaluation}

a. Rencana Pengujian

Rencana pengujian perangkat lunak pada aplikasi web media sosial di prodi informatika yaitu dengan 
menggunakan pengujian black box. Pengujian black box berfokus pada pada persyaratan fungsional perangkat lunak yang dibuat. Berikut adalah rencana pengujian aplikasi web media sosial di prodi informatika UNSRAT.

\begin{tabular}{|l|l|l|l|}
\hline Kelas Uji & Butir Uji & $\begin{array}{c}\text { Tingkat } \\
\text { Pengujia } \\
\mathrm{n}\end{array}$ & $\begin{array}{c}\text { Jenis } \\
\text { Pengujia } \\
\mathrm{n}\end{array}$ \\
\hline Login User & $\begin{array}{l}\text { Pengecekan } \\
\text { User Yang } \\
\text { Terdaftar }\end{array}$ & Integrasi & $\begin{array}{l}\text { Black } \\
\text { Box }\end{array}$ \\
\hline $\begin{array}{l}\text { Form } \\
\text { Pertanyaan }\end{array}$ & $\begin{array}{l}\text { Menginput } \\
\text { Pertanyaan } \\
\text { Yang ada }\end{array}$ & Integrasi & $\begin{array}{l}\text { Black } \\
\text { Box }\end{array}$ \\
\hline $\begin{array}{l}\text { Form } \\
\text { Komentar }\end{array}$ & $\begin{array}{l}\text { Menginput } \\
\text { Komentar } \\
\text { Yang Ada }\end{array}$ & Integrasi & $\begin{array}{l}\text { Black } \\
\text { Box }\end{array}$ \\
\hline $\begin{array}{l}\text { Form } \\
\text { Pengumuma } \\
\mathrm{n}\end{array}$ & $\begin{array}{l}\text { Menginput } \\
\text { Pengumuma } \\
\mathrm{n} \text { Yang Ada }\end{array}$ & Integrasi & $\begin{array}{l}\text { Black } \\
\text { Box }\end{array}$ \\
\hline
\end{tabular}

Gambar 16. Halaman Rencana Pengujian

\section{PENUTUP}

\section{a. Kesimpulan :}

Berdasarkan dari proses-proses yang ada, maka kesimpulan dari pembuatan skripsi tentang implementasi web media sosial di prodi informatika universitas samratulangi yaitu membangun media sosial sendiri di prodi informatika Unsrat serta Mendigitalisasikan aktivitas tanya jawab di prodi informatika ke dalam media sosial.

\section{b. Saran :}

Jika ada pengembangan lain mengenai aplikasi ini saya menyarankan agar pengembang lain akan melanjutkan fitur-fitur yang tidak sempat dibuat oleh pengembang yang lalu dan melengkapi kekurangan-kekurangan dari aplikasi ini akan tetapi tetap mengikut perancangan yang telah ada.

\section{DAFTAR REFERENSI}

[1] Andreas M. Kaplan, Michael Haenlein. 2010. User Of TheWorld, Unite! The Challenges And Opportunities Of Media Sosial. Prancis

[2] Arief, M.Rudianto. 2011. Pemrograman Web Dinamis Menggunakan Php dan MySQL CV Andi Offset. Yogyakarta.

[3] Bosword, A. 2003. Designing Data-Intensive Web Applications. San Fransisco. United States of America.
[4] Hamzah, H, dkk. 2016. Analisa Perancangan Website Media Sosial ( Studi Kasus Program Studi Informatika UNSRAT ) Manado, Indonesia.

[5] Mulyanti, A, dkk sebagai Tim Pusat Humas Kementrian Perdagangan RI. 2014. Panduan Optimalisasi Media Sosial untuk Kementerian Perdagangan RI. Jakarta Pusat.

[6] Sofwan A. 2003 Belajar PHP dengan Framework Code Igniter. Jakarta.

[7] Solichin, A. 2010. MySQL 5 Dari Pemula Hingga Akhir. Jakarta.

[8] Pressman, R. 2002. Rekayasa Perangkat Lunak. Florida . United States of America

[9] TI Unsrat Web Development Team, Sejarah Teknik Informatika Unsrat. http://fatek.unsrat.ac.id/informatika/index.php/tent ang-kami/profil, Diakses terakhir pada tanggal 15 Juni 2016.

\section{SEKILAS TENTANG PENULIS}

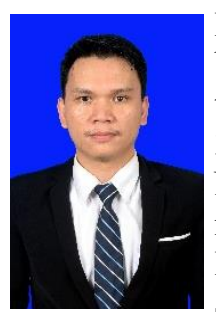

Kristopper Morris Rompis lahir di imandi bolaang mongondow Sulawesi utara pada tanggal 6 desember 1991. Anak ke-2 dari 3 bersaudara dengan pendidikan SD Negeri 1 Tolondadu. Penulis lalu melanjutkan ke SMP Negeri 1 Molibagu. Lalu ke SMA Negeri 1 Tomohon.

Sebelum kuliah penulis sempat bekerja direstoran cina yang ada di batam selama hampir 1 tahun dan setelah itu pada tahun 2011 penulis kemudian melanjutkan studi di Fakultas Teknik, Jurusan Elektro, Program Studi Informatika, Universitas Sam Ratulangi Manado. Pada Tahun 2015 bulan oktober mengikuti keluarnya surat penunjukan komisi pembimbing dan penetapan judul skripsi, penulis membuat Skripsi demi memenuhi syarat Sarjana (S1) dengan penelitian berjudul Implementasi Web Media Sosial Di Program Studi Informatika Universitas Sam Ratulangi yang dibimbing oleh dua dosen pembimbing yaitu Dr. Eng Steven R. Sentinuwo, ST., MTI. dan Xaverius B.N Najoan, ST.,MT. Penulis dinyatakan lulus dari Program Studi Teknik Informatika Jurusan Elektro Universitas Sam Ratulangi Manado pada tanggal 07 Maret 2017. 